\title{
Microbial Metabolism of Rofecoxib, A Selective COX-2 Inhibitor
}

\author{
Khaled Y. Orabi*
}

\begin{abstract}
Department of Pharmaceutical Chemistry, Faculty of Pharmacy, Health Sciences Center, Kuwait University, Safat 13110, Kuwait
\end{abstract}

\begin{abstract}
Microbial transformation studies of rofecoxib (1), a potent selective cyclooxygenase-2 inhibitor, using sixty microorganisms, mainly fungi and actinomycetes, have revealed that it was metabolized by three microorganisms. Using a standard two-stage screening technique, Cunninghamella echinulata var. echinulata ATCC 9244, Mucor griseocyanus ATCC 1207b, and Rhizopus oryzae ATCC 34121 showed two common more polar metabolites 2 and 3. Moreover, it was apparent that Cunninghamella echinulata var. echinulata was the most efficient microorganism to almost completely metabolize 1, and hence, was selected for preparative scale fermentation. These metabolites were characterized on the basis of their spectral data as 4'-hydroxyrofecoxib (2) and 3'-hydroxyrofecoxib (3).
\end{abstract}

Keywords: Rofecoxib, Cunninghamella echinulata var. echinulata, 4'-hydroxyrofecoxib, 3'-hydroxyrofecoxib, COX-2 inhibitor.

\section{INTRODUCTION}

The enzyme prostaglandin cyclooxygenase, COX, catalyzes the rate-limiting cyclization step in the formation of prostanoids from arachidonic acid [1,2]. Two isoforms of the COX enzyme have been characterized; COX-1 and COX-2 [3]. The discovery of COX-2 has provided the rationale for the development of a new class of the non-steroidal anti-inflammatory drugs (NSAIDs), the selective COX-2 inhibitors, coxibs. These agents were developed on the premise that selective inhibition of COX-2 would result in decreased inflammation without the adverse gastrointestinal effects associated with inhibition of COX-1 [4-6]. Rofecoxib and celecoxib were the first selective COX-2 inhibitors approved by the US Food and Drug Administration for the treatment of rheumatoid arthritis, osteoarthritis and for relief of acute pain associated with dental surgery and primary dysmenorrhea. Rofecoxib is a diarylfuranone derivative containing a phenylsulphone moiety that interacts with COX-2 side pocket [7]. This interaction represents an important determinant for COX-2 selectivity. In fact, rofecoxib almost completely inhibits monocyte COX-2 activity without affecting COX-1 activity [8].

On September 30, 2004, Merck and Co. voluntary withdrew rofecoxib, $\mathrm{VIOXX}{ }^{\circledR}$, from the market due to increased risk of cardiovascular toxicities associated with the drug [9]. It is not clear whether these toxicities are due to rofecoxib high COX-2 selectivity. It was shown that COX-2 inhibitors decrease vascular

*Address corresponding to this author at the Department of Pharmaceutical Chemistry, Faculty of Pharmacy, Health Sciences Center, Kuwait University, Safat 13110, Kuwait; Tel: (965)-2-498-6048; Fax: (965)-2-498-6898; E-mail: kyorabi@hsc.edu.kw prostacyclin $\mathrm{PGI}_{2}$ production and may disrupt the homeostatic mechanisms that limit the effects of platelets activation. Therefore, the mechanism of this cardiovascular toxicity could lie in the inhibition of COX2 itself, and thus be a class effect. On the other hand, it may be due to its unique chemical structure, its pharmacokinetics and/or the presence of toxic metabolites [9]. In order to explore more this hypothesis, rofecoxib metabolites need to be prepared in quantities enough to be identified and evaluated for possible activity and/or toxicity.

In drug research and development, metabolism is of a pivotal importance due to the interconnectedness between pharmacokinetic and pharmacodynamic processes. The phenomenon of metabolism originates from the fact that mammals usually treat any exogenous drug as non-self and work hard to weaken the effect and/or the concentration of this "foreign" substance through enzymatic machinery. However, xenobiotic metabolic system sometimes generates products more reactive and biologically destructive than the original substrate. The metabolism process generates new chemical entities, metabolites, which may have distinct pharmacodynamics and toxicodynamic properties of their own [10].

Human metabolism of rofecoxib is primarily mediated through reduction by cytosolic enzymes. The principal metabolic products are the cis- and transdihydro derivatives of rofecoxib. An additional metabolite was recovered as the glucuronide of the hydroxy derivative, a product of oxidative metabolism. Cytochrome P450 plays a minor role in metabolism of rofecoxib. This was concluded since rofecoxib disposition was not affected by the inhibition of CYP $3 \mathrm{~A}$ activity after the administration of ketoconazole. 
However, induction of general hepatic metabolic activities by administration of the non-specific inducer rifampin, produces a $50 \%$ decrease in rofecoxib plasma concentrations $\left(\mathrm{VIOXX}^{\circledR}\right.$ insert).

The use of microbial systems as in vitro models for drug metabolism in humans was first formalized by Rosazza and Smith [11], and was defined as the use of microorganisms, bacteria, yeasts, and fungi, to facilitate the study of xenobiotic biotransformation in mammals, including man.

It is anticipated that the microbial metabolism of rofecoxib would produce significant quantities of metabolites that would be difficult to obtain from either animal systems or chemical synthesis. Moreover, this work will also provide some new analogs that may serve as prospective candidates for their potential pharmacological action and/or cardiac toxicity evaluation, or as starting compounds for the semisynthesis of other derivatives.

\section{MATERIALS AND METHODS}

Rofecoxib used in this project was obtained as a gift (The Egyptian International Pharmaceutical Industries Co, $10^{\text {th }}$ of Ramadan City, Egypt). The identity of the substrate was positively confirmed as a pure rofecoxib via NMR analyses. The microbial cultures used in this project were originally obtained from the American Type Culture Collection (ATCC, Rockville, Maryland, USA) and from the US Department of Agriculture Northern Regional Research Laboratories (NRRL, Peoria, Illinois, USA). All the preliminary screening and preparative-scale experiments were carried out in medium $\alpha$, which consists of, per liter of distilled water, glucose, $20 \mathrm{gm}$; NaCl, $5 \mathrm{gm} ; \mathrm{K}_{2} \mathrm{HPO}_{4}, 5 \mathrm{gm}$; yeast extract (BBL, Cockeysville, Maryland, USA), $5 \mathrm{gm}$; peptone (Difco, Detroit, Michigan, USA), $5 \mathrm{gm}$. TLC analyses were performed on precoated silica gel 60 $F_{254}$ plates (Merck, New Jersey, USA). The adsorbent used for column chromatography was Si gel 60/230400 mesh (EM Science, Humble, Texas, USA). All solvents used for chromatographic purposes were of analytical grade, solvent used for UV analysis was of spectral grade, and those used for extraction processes were general purpose reagents.

The compounds IR spectra were recorded as neat solids using an FTIR-4100 Jasco spectrophotometer (Jasco, Easton, Maryland, USA). UV spectra were measured in methanol using a UV-160 IPC UV-visible dual-beam spectrophotometer. The ${ }^{1} \mathrm{H}$ and ${ }^{13} \mathrm{C}$ NMR were obtained on a Bruker DPX-400 spectrometer
(Bruker Bio Spin, Rheinstetten, Germany) operating at 400 and $100 \mathrm{MHz}$, respectively. Both ${ }^{1} \mathrm{H}$ and ${ }^{13} \mathrm{C}$ NMR spectra were recorded in $\mathrm{CDCl}_{3}$, and the chemical shift values were expressed in $\delta(\mathrm{ppm})$ relative to the internal standard TMS. For the ${ }^{13} \mathrm{C}$ NMR spectra, the number of attached protons was determined by DEPT $135^{\circ}$. 2D NMR data were obtained using the standard pulse sequence of the Bruker DPX-400 for COSY, HSQC, and HMBC. HRMS was carried out using a Bruker Bioapex FTMS with Electrospray lonization Spectrometer (Bruker Daltonic GmbH, Bremen, Germany).

\section{Cultures and Fermentation Screening Procedure}

A total of sixty microorganisms, mainly fungi and actinomycetes, Table 1, have been screened for their ability to catalyze bioconversion of rofecoxib (1). Only three of them, Cunninghamella echinulata var. echinulata ATCC 9244, Mucor griseocyanus ATCC 1207b, and Rhizopus oryzae ATCC 34121, showed definite metabolism of rofecoxib. Stock Cultures were maintained on agar slants of media recommended by the ATCC and were stored at $4{ }^{\circ} \mathrm{C}$.

All the preliminary screening and preparative-scale experiments were carried out as reported before [12], and according to a standard two-stage protocol [13]. Substrate 1 was prepared as a $15 \%$ solution in $N, N$ dimethylformamide (DMF) and added to the 24-h-old stage II culture medium of the microorganism at a concentration $0.3 \mathrm{mg} / \mathrm{mL}$ of medium. Substrate controls were composed of sterile medium to which the substrate (4 mg/100 $\mu \mathrm{L}$ DMF) was added and incubated without microorganisms. Culture controls consisted of fermentation blanks in which the microorganisms were grown under identical conditions but without the substrate addition. After two weeks of incubation, each control was harvested and analyzed by TLC.

\section{Culture Sampling and Chromatographic Conditions}

Sampling was carried out by withdrawing $5 \mathrm{~mL}$ of culture and extracting it with $5 \mathrm{~mL}$ of ethylacetate. The concentrated organic phase was analyzed by TLC for the presence of metabolites. TLC analyses were performed using $5 \% \mathrm{MeOH}$ in $\mathrm{CHCl}_{3}$ as the solvent system. Visualization was accomplished by exposure to short wavelength UV ( $\left.\lambda_{\max } 254\right)$.

\section{Preparative Scale Conversion of Rofecoxib by Cunninghamella echinulata var. echinulata}

C. echinulata var. echinulata ATCC 9244 was grown in fifteen 1-L culture flasks each containing 200 
$\mathrm{mL}$ of medium $\alpha$. A total of $500 \mathrm{mg}$ of $\mathbf{1}$ (in $5 \mathrm{~mL}$ DMF) were evenly distributed among the 24-h-old stage II culture. After two weeks, the incubation mixtures were checked by TLC. TLC revealed that most of 1 was transformed and two more polar metabolites were produced. The incubation mixtures were combined and filtered to remove the mycelia, and the filtrate was extracted with ethylacetate $(3 \mathrm{~L} \times 4)$. The combined extracts were dried over anhydrous $\mathrm{Na}_{2} \mathrm{SO}_{4}$ and evaporated to dryness in vacuo at $40{ }^{\circ} \mathrm{C}$ to afford a yellowish residue $(0.7 \mathrm{gm})$. Part of this residue $(0.4 \mathrm{gm})$ was purified by column chromatography over silica gel $(45 \mathrm{~g}, 3.3 \times 15 \mathrm{~cm})$ using $\mathrm{MeOH}-\mathrm{CHCl}_{3}(5 \% \mathrm{v} / \mathrm{v})$ as the eluting solvent system. Fractions of $20 \mathrm{~mL}$ each were collected and pooled on the basis of TLC analyses. Fractions 15-22 yielded pure 4'-hydroxyrofecoxib (2) (33 $\mathrm{mg}, 6.2 \%$ yield), with $\mathrm{R}_{f}=0.41$. Fractions $35-43$ gave pure 3'-hydroxyrofecoxib (3) (12 mg, 2.3\% yield), with $\mathrm{R}_{f}=0.37$.

4'-hydroxyrofecoxib (2) was obtained as colorless needles; IR neat $v_{\max } 3373(\mathrm{OH}), 1746(\mathrm{C}=\mathrm{O}), 1595$ (aromatic), 1445 (aromatic) $\mathrm{cm}^{-1}$; UV $\left(\mathrm{CH}_{3} \mathrm{OH}\right) \lambda_{\max }$ (log ع) $284(4.14) \mathrm{nm} ;{ }^{1} \mathrm{H}$ NMR $\left(\mathrm{CDCl}_{3}, 400 \mathrm{MHz}\right)$ see Table 2; ${ }^{13} \mathrm{C}$ NMR $\left(\mathrm{CDCl}_{3}, 100 \mathrm{MHz}\right)$ see Table 2; High resolution ESIMS $\mathrm{m} / z \quad 330.0584 \quad[\mathrm{M}]^{+}$(calcd for $\mathrm{C}_{17} \mathrm{H}_{14} \mathrm{O}_{5} \mathrm{~S}$ 330.0562). On the other hand, 3'hydroxyrofecoxib (3) was obtained as colorless needles; IR neat $v_{\max } 3373(\mathrm{OH}), 1746(\mathrm{C}=\mathrm{O}), 1590$ (aromatic), 1461 (aromatic) $\mathrm{cm}^{-1} ; \mathrm{UV}\left(\mathrm{CH}_{3} \mathrm{OH}\right) \lambda_{\max }$ (log ع) 281 (4.12) nm; ${ }^{1} \mathrm{H}$ NMR $\left(\mathrm{CDCl}_{3}, 400 \mathrm{MHz}\right)$ see Table 2; ${ }^{13} \mathrm{C}$ NMR $\left(\mathrm{CDCl}_{3}, 100 \mathrm{MHz}\right)$ see Table 2; High resolution ESIMS $\mathrm{m} / \mathrm{z} 330.0584 \mathrm{[M}^{+}$(calcd for $\left.\mathrm{C}_{17} \mathrm{H}_{14} \mathrm{O}_{5} \mathrm{~S} 330.0562\right)$.

\section{RESULTS AND DISCUSSION}

A total of sixty microorganisms, mainly fungi and actinomycetes, Table 1, have been screened for their ability to catalyze bioconversion of rofecoxib (1). Only three of them, Cunninghamella echinulata var. echinulata ATCC 9244, Mucor griseocyanus ATCC 1207b, and Rhizopus oryzae ATCC 34121, showed definite metabolism of rofecoxib. These cultures produced two more polar metabolites, 2 and 3 . Their structures are shown in Figure 1. Thin layer chromatography, showed that Cunninghamella echinulata var. echinulata was the most efficient microorganism to almost completely metabolize rofecoxib, and hence, was selected for preparativescale fermentation.
Table 1: Microorganisms Screened for their Ability to Metabolize Rofecoxib ${ }^{a}$

\begin{tabular}{|c|}
\hline Absidia glauca ATCC 22752 \\
\hline Achlya racemosa ATCC 11392 \\
\hline Acrasis rosea ATCC 26823 \\
\hline Acrodictys erecta ATCC 24083 \\
\hline Acinetobacter calcoaceticus ATCC 14987 \\
\hline Agaricus campestris ATTCC 26815 \\
\hline Alcaligenes eutrophus ATCC 17697 \\
\hline Allomyces arbuscula ATCC 10983 \\
\hline Aspergillus flavus NRRL 501 \\
\hline Aspergillus fumigatus ATCC 26934 \\
\hline Aureobasidium pullulans ATCC 9348 \\
\hline Bacillus cereus var. fluorescens ATCC 13824 \\
\hline Beauvaria bassiana ATCC 7159 \\
\hline Bullera alba ATCC 18568 \\
\hline Calonectria decora ATCC 14767 \\
\hline Candida tropicalis ATCC 20021 \\
\hline Cantharellus cibarius ATCC 13228 \\
\hline Cellulomonas flavigena ATCC 482 \\
\hline Ceratobasidium cornigerum ATCC 38315 \\
\hline Coprinus species ATCC 16789 \\
\hline Cordyceps militaris ATCC 34164 \\
\hline Cryptococcus macerans Ziffer \\
\hline Cunninghamella blakesleeana ATCC 8688a \\
\hline Cunninghamella echinulata NRRL 3655 \\
\hline Cunninghamella echinulata var. echinulata ATCC 9244 \\
\hline Cunninghamella elegans ATCC 9245 \\
\hline Cunninghamella species NRRL 5695 \\
\hline Cylindrocephalum aureum ATCC 12720 \\
\hline Debaryomyces polymorphus ATCC 20280 \\
\hline Dictyostelium mucoroides ATCC 2682 \\
\hline Eupenicillium javanicum ATCC 26879 \\
\hline Filobasidiella neoformans ATCC 10226 \\
\hline Fusarium oxysporum ATCC 7601 \\
\hline Fusarium solani ATCC 12823 \\
\hline Geotrichum amycelicum ATCC 24658 \\
\hline Gliocladium deliquescens ATCC 10097 \\
\hline Gongronella butleri ATCC 22822 \\
\hline Hansenula anomala ATCC 20170 \\
\hline Lipomyces lipofer ATCC 107242 \\
\hline Melanospora ornata ATCC 26180 \\
\hline Melanospora parasitica ATCC 18055 \\
\hline Mortierella zonata ATCC 13309 \\
\hline
\end{tabular}


(Table 1). Continued.

\begin{tabular}{|c|}
\hline Mucor griseocyanus ATCC 1207b \\
\hline Penicillium chrysogenum ATCC 9480 \\
\hline Polyporus brumalis ATCC 34487 \\
\hline Rhizopogon species ATCC 36060 \\
\hline Rhizopus arrhizus ATCC 11145 \\
\hline Rhizopus oryzae ATCC 34121 \\
\hline Rhizopus stolonifer ATCC 24795 \\
\hline Rhodococcus species ATCC 21146 \\
\hline Saccharomyces cerevisiae ATCC 2366 \\
\hline Saccharomyces pastorianus ATCC 2366 \\
\hline Saccharomyces lipolytica ATCC 16617 \\
\hline Sepedonium chrysospermum ATCC 13378 \\
\hline Septomyxa affinis ATCC 6737 \\
\hline Streptomyces griseus ATTC 13968 \\
\hline Streptomyces rimosus NRRL 2234 \\
\hline Streptomyces roseochromogenus ATCC 13400 \\
\hline Talaromyces ucrainicus ATCC 18352 \\
\hline Thamnidium elegans ATCC 18191 \\
\hline
\end{tabular}

${ }^{a}$ Microorganisms in bold represent those gave positive results.

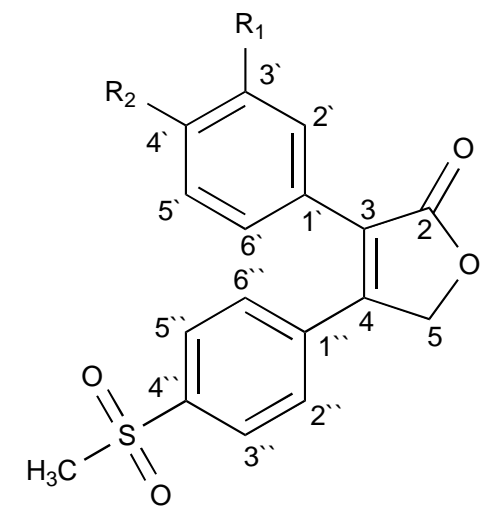

Rofecoxib (1); $\mathrm{R}_{1}=\mathrm{R}_{2}=\mathrm{H}$

4'-Hydroxyrofecoxib (2); $\mathrm{R}_{1}=\mathrm{H}, \mathrm{R}_{2}=\mathrm{OH}$

3'-Hydroxyrofecoxib (3); $\mathrm{R}_{1}=\mathrm{OH}, \mathrm{R}_{2}=\mathrm{H}$

Figure 1: Rofecoxib and its two hydroxylated metabolites.

Metabolites $\mathbf{2}$ and $\mathbf{3}$ were isolated by solvent extraction, purified by chromatography and subjected to spectral analyses.

Metabolite 2 was isolated as colorless needles in a $6.2 \%$ yield. The molecular formula was found to be $\mathrm{C}_{17} \mathrm{H}_{14} \mathrm{O}_{5} \mathrm{~S}$ on the basis of the ion peaks at $\mathrm{m} / \mathrm{z}$ $330.0584[\mathrm{M}]^{+}$, and NMR data. The IR spectrum showed a broad absorption at $v_{\max } 3373 \mathrm{~cm}^{-1}$ suggesting the presence of a hydroxyl group. However, an intermediate absorption at $v_{\max } 1746 \mathrm{~cm}^{-1}$ was also shown indicating the survival of the original $\alpha, \beta$ unsaturated 5-membered ring lactone carbonyl group in the parent compound.

Most ${ }^{1} \mathrm{H}$ and ${ }^{13} \mathrm{C}$ NMR spectral data of 2 (Table 2) were similar to those of $\mathbf{1}$ except for resonances attributed to the non-phenylsulfone aromatic ring. The ${ }^{13} \mathrm{C}$ NMR spectra revealed the presence of an oxygenated aromatic carbon signal at $\delta_{C} 157.7$ which was concluded to be attached to a hydroxyl group as suggested by the IR spectrum $\left(v_{\max } 3373 \mathrm{~cm}^{-1}\right)$ and by the presence of a $\mathrm{D}_{2} \mathrm{O}$ exchangeable proton at $\delta_{H} 3.55$. This hydroxyl group was determined from the HMBC spectra to be at C-4' due to the presence of ${ }^{3} \mathrm{~J}$ cross peaks between this carbon $\left(\delta_{C} 157.7, \mathrm{~s}\right)$ and two protons resonated at $\delta_{H} 7.58$ as doublets with a $J$ value of $8.1 \mathrm{~Hz}$. This conclusion was supported by protons coupling patterns and constants that were identical to a para-substituted aromatic ring, Table 2. COSY spectra showed a correlation between these protons and other two protons both resonated at $\delta_{H} 6.70$ as doublets with a $J$ value of $8.1 \mathrm{~Hz}$. It is noteworthy the upfield shifts of carbons $1^{\prime}, 3^{\prime}$, and $5^{\prime}(\Delta \delta 5.0 \mathrm{ppm}, 14.0 \mathrm{ppm}$, and 14.0 ppm, respectively) due to the resonance effect of the hydroxyl moiety, as an electron-donating group, on the aromatic ring. These data unambiguously determined that 2 is $4^{\prime}$-hydroxyrofecoxib (Figure $\mathbf{1}$ ).

Metabolite $\mathbf{3}$ was isolated as colorless needles in a $2.3 \%$ yield. It was shown to possess identical molecular formula to $2, \mathrm{C}_{17} \mathrm{H}_{14} \mathrm{O}_{5} \mathrm{~S}$, as derived from the presence of an ion peak at $\mathrm{m} / \mathrm{z} 330.0584[\mathrm{M}]^{+}$and from the NMR data. The presence of an additional hydroxyl group and an intact $\alpha, \beta$-unsaturated 5 -membered ring lactone carbonyl group was concluded from the IR spectrum due to the presence of absorptions at $v_{\max } 3373$ and $1746 \mathrm{~cm}^{-1}$, respectively.

${ }^{13} \mathrm{C}$ NMR showed seventeen resonances distributed as one methyl, one methylene, eight aromatic methines, and one oxygenated aromatic quaternary carbon. Other quaternary carbons were almost identical to those of the parent rofecoxib. These data showed that metabolite $\mathbf{3}$ is similar to 2, i.e., another rofecoxib hydroxy derivative. Protons coupling patterns and constants were instrumental in determining the substitution pattern of the non-phenylsulfone aromatic ring as a meta-substituted aromatic ring, Table $2 .{ }^{1} \mathrm{H}$ NMR spectrum showed that one aromatic proton resonated at $\delta_{H} 7.01$ as a singlet and was assigned $\mathrm{H}$ $2^{\prime}$. On the other hand, $\mathrm{H}-5^{\prime}$ was shown to resonate at $\delta_{H} 7.58$ as a double doublet with $J$ values of 8.1 and 
Table 2: NMR Data (400 MHz, $\mathrm{CDCl}_{3}$ ) for Rofecoxib (1) and Metabolites 2 and 3

\begin{tabular}{|c|c|c|c|c|c|c|}
\hline \multicolumn{3}{|c|}{ Rofecoxib (1) } & \multicolumn{2}{|c|}{ 4'-Hydroxyrofecoxib (2) } & \multicolumn{2}{|c|}{ 3'-Hydroxyrofecoxib (3) } \\
\hline$\#$ & $\delta_{c}, \mathbf{m}^{\mathrm{a}}$ & $\delta_{H}(J$ in Hz) & $\delta_{c}, \mathbf{m}$ & $\delta_{H}(J$ in $\mathrm{Hz})$ & $\boldsymbol{\delta}_{c}, \mathbf{m}$ & $\delta_{H}(J$ in $\mathrm{Hz})$ \\
\hline 2 & 173.1, C & - & 173.1, C & - & 173.1, C & - \\
\hline 3 & 129.6, C & - & 129.6, C & - & 129.6, C & - \\
\hline 4 & 154.0, C & - & 154.0, C & - & 154.0, C & - \\
\hline 5 & $70.9, \mathrm{CH}_{2}$ & $5.22, \mathrm{~s}$ & $70.9, \mathrm{CH}_{2}$ & $5.22, \mathrm{~s}$ & $70.9, \mathrm{CH}_{2}$ & $5.22, \mathrm{~s}$ \\
\hline $1^{\prime}$ & $130.1, \mathrm{C}$ & - & 125.1, C & - & $133.9, \mathrm{C}$ & - \\
\hline $2^{\prime}$ & 129.6, $\mathrm{CH}$ & $7.42, \mathrm{br} \mathrm{s}$ & $130.5, \mathrm{CH}$ & $7.58, d(8.1)$ & 112.1, $\mathrm{CH}$ & $7.01, \mathrm{~s}$ \\
\hline $3^{\prime}$ & $129.8, \mathrm{CH}$ & 7.42, br s & $115.8, \mathrm{CH}$ & $6.70, d(8.1)$ & $158.4, \mathrm{C}$ & - \\
\hline $4^{\prime}$ & $129.8, \mathrm{CH}$ & $7.42, \mathrm{br} \mathrm{s}$ & 157.7, C & - & $115.1, \mathrm{CH}$ & $6.80, \mathrm{~d}(8.1)$ \\
\hline $5^{\prime}$ & $129.8, \mathrm{CH}$ & 7.42, br s & $115.8, \mathrm{CH}$ & $6.70, d(8.1)$ & $130.0, \mathrm{CH}$ & $7.58, \mathrm{dd}(8.1,8.1)$ \\
\hline $6^{\prime}$ & 129.6, CH & $7.42, \mathrm{br} \mathrm{s}$ & $130.5, \mathrm{CH}$ & $7.58, \mathrm{~d}(8.1)$ & $121.5, \mathrm{CH}$ & $6.85, \mathrm{~d}(8.1)$ \\
\hline $1 "$ & $136.9, \mathrm{C}$ & - & $136.9, \mathrm{C}$ & - & $136.9, \mathrm{C}$ & - \\
\hline $2^{\prime \prime}$ & 129.1, CH & $7.53, d(8.3)$ & $129.1, \mathrm{CH}$ & $7.53, d(8.3)$ & 129.1, CH & $7.53, \mathrm{~d}(8.3)$ \\
\hline $3^{\prime \prime}$ & $128.7, \mathrm{CH}$ & $7.94, d(8.3)$ & $128.7, \mathrm{CH}$ & $7.94, d(8.3)$ & $128.7, \mathrm{CH}$ & $7.94, d(8.3)$ \\
\hline $4 "$ & 142.6, C & - & 142.6, C & - & 142.6, C & - \\
\hline $5^{\prime \prime}$ & $128.7, \mathrm{CH}$ & $7.94, d(8.3)$ & $128.7, \mathrm{CH}$ & $7.94, d(8.3)$ & $128.7, \mathrm{CH}$ & $7.94, d(8.3)$ \\
\hline 6" & $129.1, \mathrm{CH}$ & $7.53, d(8.3)$ & $129.1, \mathrm{CH}$ & $7.53, \mathrm{~d}(8.3)$ & $129.1, \mathrm{CH}$ & $7.53, \mathrm{~d}(8.3)$ \\
\hline $\mathrm{CH}_{3}$ & $44.9, \mathrm{CH}_{3}$ & $3.09, \mathrm{~s}$ & $44.9, \mathrm{CH}_{3}$ & $3.09, \mathrm{~s}$ & $44.9, \mathrm{CH}_{3}$ & $3.09, \mathrm{~s}$ \\
\hline $\mathrm{OH}$ & - & - & - & $3.55, \mathrm{br} \mathrm{s}^{\mathrm{b}}$ & - & 3.55, br s $^{b}$ \\
\hline
\end{tabular}

${ }^{a}$ Carbon multiplicities were determined by DEPT $135^{\circ}$.

${ }^{\mathrm{b}} \mathrm{D}_{2} \mathrm{O}$ exchangeable protons.

8.1 $\mathrm{Hz}$. This proton was further shown to possess three-bond correlation with the oxygenated aromatic carbon $\left(\delta_{C} 158.4, \mathrm{~s}, \mathrm{C}-3^{\prime}\right)$. Another important change in the NMR data was the upfield shifts of carbons $2^{\prime}, 4^{\prime}$, and $6^{\prime}(\Delta \delta 17.5 \mathrm{ppm}, 14.7 \mathrm{ppm}$, and $8.1 \mathrm{ppm}$, respectively) due to the resonance effect of the hydroxyl moiety, as an electron-donating group, on the aromatic ring. Other NMR assignments were similar to those of rofecoxib, Table 2 . These data confirmed the identity of $\mathbf{3}$ as $\mathbf{3}^{\prime}$-hydroxyrofecoxib (Figure 1).

Several animal metabolites were previously reported including 5-hydroxyrofecoxib, 5hydroxyrofecoxib-O- $\beta$-D-glucuronide, cis- and trans3,4-dihydrorofecoxib, rofecoxib-3',4'-dihydrodiol, and 4'-hydroxyrofecoxib sulfate [14]. Additionally, cis- and trans-3,4-dihydrorofecoxib, 5-hydroxyrofecoxib, 4'- and 5 -hydroxyrofecoxib-O- $\beta$-D-glucuronide, rofecoxib- $3^{\prime}, 4^{\prime}$ trans-dihydrodiol, rofecoxib-erthyro-3,4-dihydrohydroxy acid, and rofecoxib-threo-3,4-dihydrohydroxy acid were isolated and identified from human urine [15]. However, none of the microbial metabolites were reported before.

Although, compounds 2 and $\mathbf{3}$ were reported from total chemical synthesis, along with their acetyl derivatives [16], they were prepared using a tedious six-step reaction sequence giving only $5 \%$ cumulative yields. Additionally, full spectral identification of metabolites $\mathbf{2}$ and $\mathbf{3}$ were never provided in this study. Comparatively, in the current report, these metabolites were microbially produced using cheap and readily available microorganisms and medium constituents. The yield of the produced compounds can be proportionally increased by increasing the fermentation culture volume. Moreover, full spectral data and analysis of compounds $\mathbf{2}$ and $\mathbf{3}$ are provided herewith.

This study demonstrated the potential ability of microbial models to prepare known or novel metabolites in quantities that would be difficult to obtain from either mammals or chemical routes. The formation of rofecoxib metabolites 2 and $\mathbf{3}$ using the abovementioned protocol made it possible to furnish these metabolites in significant quantities enough for cardiac toxicity evaluation. Such a study findings should help in explaining if rofecoxib cardiac toxicity is classdependent, being a selective COX-2 inhibitor, or member-dependent due its unique chemical structure. Moreover, the produced metabolites might serve as starting compounds for the semisynthesis of other more promising inhibitors. 


\section{ACKNOWLEDGEMENTS}

The Egyptian International Pharmaceutical Industries Co (EIPICO), Egypt, is acknowledged for its valuable gift of rofecoxib. This work was supported by Kuwait University, Research Grant number PC01/06. NMR analyses were carried out at Science Analytical Facility, Faculty of Science, Kuwait University, supported by Grants number GS01/01 and GS01/03.

\section{REFERENCES}

[1] Dennis EA. Phospholipase $A_{2}$ in eicosanoid generation. Am J Respir Crit Care Med 2000; 161: S32-35.

[2] Marnett LJ, Rowlinson SW, Goodwin DC, Kalgutkar AS, Lanzo CA. Arachidonic acid oxygenation by COX-1 and COX-2. Mechanisms of catalysis and inhibition. J Biol Chem 1999; 13: 22903-6.

http://dx.doi.org/10.1074/jbc.274.33.22903

[3] Xie W, Chipman JG, Robertson DL, Erikson RL, Simmons DL. Expression of a mitogen-responsive gene encoding prostaglandin synthase is regulated by mRNA splicing. Proc Natl Acad Sci USA 1991; 88: 2692-6. http://dx.doi.org/10.1073/pnas.88.7.2692

[4] Vane JR, Botting RM. Overview-mechanisms of action of anti-inflammatory drugs. In: Vane JR, Botting J, Botting R, Ed. Improved non-steroidal anti-inflammatory drugs. $1^{\text {st }}$ ed. London: Kluwer Academic Publishers and William Harvey Press 1996; pp. 1-27. http://dx.doi.org/10.1007/978-94-010-9029-2 1

[5] Donnelly MT, Hawkey CJ. COX-II inhibitors-a new generation of safer NSAIDs? Aliment Pharmacol Ther 1997; 11: 227-36. http://dx.doi.org/10.1046/j.1365-2036.1997.154330000.x

[6] Jouzeau J-Y, Terlain B, Abid A, Nedelec E, Netter P. Cyclooxygenase isoenzymes. How recent findings affect thinking about nonsteroidal anti-inflammatory drugs. Drugs 1997; 53: 563-82.

http://dx.doi.org/10.2165/00003495-199753040-00003
[7] Walker MC, Kurumbail RG, Kiefer JR, Moreland KT, Koboldt $\mathrm{CM}$, Isakson PC. A three-step kinetic mechanism for selective inhibition of cyclo-oxygenase-2 by diarylheterocyclic inhibitors. Biochem J 2001; 357: 709-18.

http://dx.doi.org/10.1042/0264-6021:3570709

[8] Ehrich EW, Dallob A, De Lepeleire I, Van Hecken A, Riendeau D, Yuan W. Characterization of rofecoxib as a cyclooxygenase-2 isoform inhibitor and demonstration of analgesia in the dental pain model. Clin Pharmacol Ther 1999; 65: 336-47. http://dx.doi.org/10.1016/S0009-9236(99)70113-X

[9] Neal MD, Fakhreddin J. COX-2 selective inhibitors cardiac toxicity: getting to the heart of the matter. J Pharm Pharmaceut Sci 2004; 7: 332-6.

[10] Orabi KY. Microbial models of mammalian metabolism. Sampangines. In: Atta-Ur-Rahman, editor. Studies in natural products chemistry-Bioactive natural products, Part D. New York: Elsevier 2000; pp. 3-49.

[11] Rosazza JP, Smith RV. Microbial models of mammalian metabolism. Appl Microbiol 1979; 25: 169-208. http://dx.doi.org/10.1016/S0065-2164(08)70150-3

[12] Orabi KY, Li E, Clark AM, Hufford CD. Microbia transformation of sampangine. J Nat Prod 1999; 62: 988-92. http://dx.doi.org/10.1021/np980457a

[13] Rosazza JP, Smith RV. Microbial models of mammalian metabolism. J Pharm Sci 1975; 64: 1733-59.

[14] Halpin RA, Geer LA, Zhang KE, et al. The absorption, distribution, metabolism and excretion of rofecoxib, a potent and selective COX-2 inhibitor, in rats and dogs. Drug Metab Dispos 2000; 28: 1244-54.

[15] Halpin R, Porras A, Geer L, et al. The disposition and metabolism of rofecoxib, a potent and selective cyclooxygenase-2 inhibitor, in human subjects. Drug Metab Dispos 2002; 30: 684-93.

\section{http://dx.doi.org/10.1124/dmd.30.6.684}

[16] Abdul Rahim M, Praveen PN, Knaus EE. Isomeric acetoxy analogues of rofecoxib: a novel class of highly potent and selective cyclooxygenase-2 inhibitors. Bioorg Med Chem Lett 2002; 12: 2753-56. http://dx.doi.org/10.1016/S0960-894X(02)00537-1

\section{DOI: http://dx.doi.org/10.6000/1927-3037.2012.01.04.3}

(C) 2012 Khaled Y. Orabi; Licensee Lifescience Global.

This is an open access article licensed under the terms of the Creative Commons Attribution Non-Commercial License (http://creativecommons.org/licenses/by-nc/3.0/) which permits unrestricted, non-commercial use, distribution and reproduction in any medium, provided the work is properly cited. 